\title{
Ecologically justified charisma: preservation of top predators delivers biodiversity conservation
}

\author{
FABRIZIO SERGIO, ${ }^{*}$ IAN NEWTON, $\ddagger$ LUIGI MARCHESI† and \\ PAOLO PEDRINI† \\ *Department of Applied Biology, Estación Biológica de Doñana, CSIC, Avda. María Luisa s/n, Pabellón del Perú, \\ 41013 Seville, Spain; †Raptor Conservation Research Unit, Trento Museum of Natural Sciences, Via Calepina 14, \\ 38100 Trento, Italy; and $\ddagger$ Centre for Ecology and Hydrology, Monks Wood, Abbots Ripton, Huntingdon, \\ Cambridgeshire PE28 2LS, UK
}

\section{Summary}

1. Because of their popular appeal, top vertebrate predators have frequently been used as flagship or umbrella species to acquire financial support, raise environmental awareness and plan systems of protected areas. However, some have claimed that the utilization of charismatic predators may divert a disproportionate amount of funding to a few glamorous species without delivering broader biodiversity benefits, an accusation aggravated by the fact that the conservation of top predators is often complex, difficult and expensive. Therefore, tests are needed of whether apex predators may be employed to achieve ecosystem-level targets.

2. To test such a hypothesis, we compared the biodiversity values recorded at the breeding sites of six raptor species, differing widely in diet and habitat associations, with those observed at three types of control locations, (i) sites randomly chosen in comparable habitat, (ii) breeding sites of a randomly selected bird species of lower trophic level and (iii) breeding sites of a lower trophic level species with specialized ecological requirements. Biodiversity was measured as the richness and evenness of bird, butterfly and tree species.

3. Biodiversity levels were consistently higher at sites occupied by top predators than at any of the three types of control sites. Furthermore, sites occupied by top predators also held greater densities of individual birds and butterflies (all species combined) than control sites.

4. In a reserve-selection simulation exercise, networks of protected sites constructed on the basis of top predators were more efficient than networks based on lower trophic level species, enabling higher biodiversity coverage to be achieved with a smaller number of reserves.

5. Synthesis and applications. Our results provide evidence of a link between the strategic utilization of top predatory species and ecosystem-level conservation. We suggest that, at least in some biological systems, conservation plans based on apex predators could be implemented to deliver broader biodiversity benefits.

Key-words: carnivores, flagships, indicator species, raptors, surrogate species, vertebrate predators

Correspondence: Dr Fabrizio Sergio, Department of Applied Biology, Estación Biológica de Doñana, CSIC, Avda. de María Luisa s/n, Pabellón del Perú, 41013 Seville, Spain (e-mail fabrizio.sergio8@tin.it; fsergio@ebd.csic.es).

\section{Introduction}

Top vertebrate predators have fascinated humans for millennia. Conservationists have frequently exploited such charisma by using top predators as flagship or umbrella species to acquire financial support (White 
et al. 1997; Gittleman et al. 2001), raise environmental awareness (Reading \& Clark 1996; Leader-Williams \& Dublin 2000) and plan systems of protected areas (Murphy \& Noon 1992; Andelman \& Fagan 2000; Carroll, Noss \& Paquet 2001). The fascination that these species exert on the general public is exemplified by economic estimates of their value for the tourism industry: in the 1980s, a single lion Panthera leo L. in Amboseli National Park, Kenya, was valued at US\$ 128750 year $^{-1}$ (Western 1984) and a leopard Panthera pardus L. in Londoloze Game Reserve, South Africa, at US\$ 50000 year $^{-1}$ (Martin \& de Meulenaer 1988), while the introduction of lions to Pilanesberg National Park, South Africa, was estimated to generate US\$ 9 million year ${ }^{-1}$ to the regional economy (McNeely 2000).

Even though flagship species can be used to raise funds spent on wider ecosystem-level targets (Caro \& O’Doherty 1999; Carignan \& Villard 2002), it has been claimed that the utilization of such species may divert a disproportionate amount of conservation action to a few glamorous species without delivering broader biodiversity benefits (Kerr 1997; Andelman \& Fagan 2000; Entwistle \& Dunstone 2000; Linnell, Swenson \& Andersen 2000). Such accusations are aggravated by the fact that the conservation of top predators is complex, politically difficult and often costly (Yalden 1993; Reading \& Clark 1996; Sergio, Marchesi \& Pedrini 2003a). For example, proactive and reactive compensation schemes for livestock losses to predators easily added up locally to US\$ 100000 year $^{-1}$ (Yalden 1993; Patterson et al. 2004), while at the individual household level livestock losses to canids and felids amounted to up to half the average annual per capita income of Nepal in the 1990s (Mishra 1997). The 'missed revenue' from unprocessed trees in a single spotted owl Strix occidentalis territory has been estimated at approximately US\$ 8 million (Biles \& Noon 1990). Furthermore, it has been argued that the fact that some conservation organizations raise funds by using species known a priori to be appealing to the public may create a vicious cycle by which conservation projects are prioritized on unscientific grounds (Entwistle \& Dunstone 2000). Therefore, more data are needed to test whether charismatic top predators can be employed reliably to achieve ecosystem-level conservation targets. We have used data on six alpine raptor species, differing widely in diet, habitat associations and general ecology, to examine whether top predators are consistently associated with high biodiversity levels. We assumed that top predators are mainly used by conservation biologists as flagship species and attempted to answer the following questions. (i) Do sites occupied by top predators show disproportionate biodiversity value? (ii) Does the protection of these sites allow us to protect disproportionate amounts of other taxa? The first question tested whether top predators may be employed as biodiversity indicator species, the second whether they may be used as umbrella species (for definitions of surrogate species see Caro \& O’Doherty 1999; Caro et al. 2004). Overall, we examined the possibility that, for top predators, the strategic concept of flagship species coincides with the functional concept of indicator and umbrella species.

\section{Methods}

The six species of diurnal and nocturnal raptors (we use the term raptor to include both the diurnal and nocturnal species) used in this study were the goshawk Accipiter gentilis L., pygmy owl Glaucidium passerinum L., Tengmalm's owl Aegolius funereus L., tawny owl Strix aluco L., long-eared owl Asio otus L. and scops owl Otus scops $\mathrm{L}$. The diet of these six species consists mainly of medium-sized birds and mammals (for the goshawk), small mammals and birds (Tengmalm's owl), small birds (pygmy owl), small mammals (tawny owl and long-eared owl), and arthropods and small vertebrates (scops owl) (Cramp \& Simmons 1980; L. Marchesi et al. unpublished data). In our study area, the main breeding habitat was mature (coniferous and mixed coniferous-broadleaved) forest for the goshawk, Tengmalm's owl and pygmy owl, younger woodland managed by stool-shoot regeneration (coppice) for the tawny owl, grassland for the scops owl and an intensive farmland-woodland mosaic for the long-eared owl. Overall, the various species spanned a wide range of diel activity pattern (diurnal or nocturnal), habitat associations and resource use.

Each species was surveyed in a different area, but all areas were located in the central-eastern Italian Alps. The territories of each species were known at the beginning of this study as part of a wider investigation of the whole alpine raptor community (Sergio, Marchesi \& Pedrini 2003a,b, 2004a; Sergio et al. 2004b, 2004c, 2005). Goshawks were surveyed in a $700-\mathrm{km}^{2}$ plot $\left(46^{\circ} 22^{\prime} \mathrm{N}, 11^{\circ} 02^{\prime} \mathrm{E}\right.$, containing 25 territories), Tengmalm's owls in a $553-\mathrm{km}^{2}$ plot $\left(46^{\circ} 26^{\prime} \mathrm{N}, 11^{\circ} 08^{\prime} \mathrm{E}, 31\right.$ territories), pygmy owls in a $539-\mathrm{km}^{2}$ plot $\left(46^{\circ} 20^{\prime} \mathrm{N}, 11^{\circ} 01^{\prime} \mathrm{E}, 32\right.$ territories), tawny owls in a $55-\mathrm{km}^{2}$ plot $\left(45^{\circ} 49^{\prime} \mathrm{N}\right.$, $11^{\circ} 57^{\prime} \mathrm{E}, 33$ territories), long-eared owls in a $155-\mathrm{km}^{2}$ plot $\left(46^{\circ} 04^{\prime} \mathrm{N}, 11^{\circ} 08^{\prime} \mathrm{E}, 32\right.$ territories) and scops owls in a $50-\mathrm{km}^{2}$ plot $\left(45^{\circ} 47^{\prime} \mathrm{N}, 11^{\circ} 07^{\prime} \mathrm{E}, 40\right.$ territories).

In all these study areas, we used the diversity of birds as a surrogate of biodiversity (Gaston 1996; Norris \& Pain 2002) and, for grassland and farmland sites, we assessed the diversity of butterfly species (Rhopalocera). These two taxa are commonly used for biodiversity assessment because of their visibility, ease of census and positive relationship with the diversity of other taxa (Gaston 1996; Kerr, Sugar \& Packer 2000; Norris \& Pain 2002). We censused birds by song recognition during point counts (Bibby, Burgess \& Hill 1992) and butterflies by capturing all those seen within $10 \mathrm{~m}$ of a rectilinear 20-m transect (i.e. in a $20 \times 20-\mathrm{m}$ quadrat). Before releasing them, all butterflies were identified 
to species level according to Tolman (1997), except for species of the genus Plebejus and Thymelicus, which were identified only to genus level (counting them as equivalent to one species). All point counts were conducted in May-June, during the first $4 \mathrm{~h}$ after sunrise. At each site (breeding or control site, see below), we conducted a 10-min point count and then slowly walked $500 \mathrm{~m}$ in each of the four main cardinal directions, noting all bird species not previously recorded. Therefore each assessment reflected the biodiversity of an area of approximately $1 \mathrm{~km}^{2}$. The assessments were conducted in 2002-03 for the Tengmalm's owl (15 breeding sites in 2002, 10 breeding sites in 2003), in 2003 for the scops owl, in 2005 for the long-eared owl and in 2004 for the other three species. To provide a further estimate of biodiversity that was less linked, in a trophic sense, to the raptor species, we also recorded the number of tree species observed during each point count.

Conducting experiments on top vertebrate predators is usually impossible for logistical, ethical and legal reasons (Duffy 2002). Therefore, to test whether sites occupied by raptors for breeding were consistently associated with high biodiversity levels, we compared such occupied sites with two types of control sites: (i) sites randomly selected within each study area (spatial control sites) and (ii) nests of a randomly selected bird species at a lower trophic level (taxonomic A control sites). Because the latter procedure may have resulted in a set of abundant generalist species that were poor biodiversity indicators, we provided a complementary test by locating the nests of another set of six lower trophic level bird species that were less abundant and with more specialized ecological requirements (taxonomic B control sites). The comparison with spatial controls was intended to test whether the occurrence of top predators could be used to detect biodiversity hotspots, while the comparison with taxonomic controls tested whether top predators may be more efficient biodiversity indicators than other species (for a similar approach see Caro et al. 2004). In all experiments, we randomly selected 25 nest sites for each raptor species and compared their biodiversity levels with those of 25 spatial controls, 25 taxonomic A controls and 25 taxonomic B controls. Spatial control sites were selected in the following matched way, to control for the potentially confounding effects of habitat. For each raptor nest $x$ in study area $y$, we selected a spatial control site that was (i) located within $y$, (ii) at the same altitude as $x$, (iii) in the same vegetation type as $x$, (iv) at a similar distance to habitat edges as $x$, (v) farther than $1 \mathrm{~km}$ from any other raptor or control site, to minimize spatial autocorrelation, and (vi) in a patch with a vegetation structure judged to be similar to $x$ (e.g. if a raptor site was located in a mature, multilayered forest with three strata, the spatial control was located in a forest with similar characteristics). Spatial controls were originally plotted, imposing con- ditions (i-v) above, by means of the animal movement extension of the GIS software ArcView 3.2 (Hooge \& Eichenlaub 1997) and then checked by ground surveys. If condition (vi) did not hold, the process was repeated until a suitable site was found. Taxonomic A control sites were chosen in the following manner. (i) For a raptor species in study area $y$, we listed all the species of lower trophic levels that were known from local atlas data to occupy the same habitat type; (ii) we then randomly selected one of them; (iii) 25 random locations were plotted within $y$; (iv) we visited each one and found the nearest nest of the selected species. The taxonomic control species were the robin Erithaculus rubecula L., blackbird Turdus merula L., blackcap Sylvia atricapilla L., crested tit Parus cristatus L., chaffinch Fringilla coelebs L. and European goldfinch Carduelis carduelis L. We selected as taxonomic B control species the hazel grouse Bonasa bonasia L., European nightjar Caprimulgus europaeus L., green woodpecker Picus viridis L., grey-headed woodpecker Picus canus Gmelin and Eurasian treecreeper Certhia familiaris L., and censused 25 nests of each species in the same manner as for taxonomic A controls. Finally, for each nest of the taxonomic control species, we plotted a spatial control site (procedure as above) to test further whether such randomly selected, lower trophic level, species could also be employed as biodiversity indicators.

Furthermore, for each type of location (predator site, spatial control and taxonomic control) we conducted a simulation of a reserve network selection, following Kerr (1997) (see also Jeggins 2000). For each group of 25 sites, we (i) selected the site with the highest richness of bird species and (ii) progressively added sites with sets of species most complementary to those already selected, until all avian species were represented in a hypothetical reserve network. The aim in each case was to find the minimum number of reserves necessary to contain all species encountered during the study.

Comparisons between raptor breeding sites and spatial and taxonomic controls were performed by means of $t$-tests (Sokal \& Rohlf 1981). For each sampled site, biodiversity was expressed as: (i) the total numbers of all species; (ii) the numbers of avian species classified as vulnerable (Species of European Conservation Concern (SPEC) 1-4; Tucker \& Heath 1994); (iii) the Shannon-Wiener diversity index (Krebs 1998) calculated on all species; and (iv) the Shannon-Wiener diversity index calculated on vulnerable species only. In each comparison, we excluded from biodiversity estimates the species that were the subject of the test.

Conservation areas are sometimes selected not on the total numbers of species they hold, but on the densities of individuals of particular species of interest (Caro et al. 2004 and references therein). We therefore conducted a further series of analyses as described above but with the total numbers of individual birds or butterflies, rather than the biodiversity index, as the dependent variable.

In all analyses, means are given $\pm 1 \mathrm{SE}$, tests are twotailed and statistical significance was set at $\alpha \leq 0 \cdot 05$. 
Fig. 1. Biodiversity estimates collected at sites occupied by six top predators, at randomly selected sites (spatial control sites), sites occupied by six randomly selected, lower trophic level species (taxonomic A control sites) and sites occupied by six lower trophic level species with specialized ecological requirements (taxonomic B control sites). Top predator sites are shown in black and control sites in white. Values represent averages \pm $1 \mathrm{SE}$; (a) numbers of all species; (b) numbers of species classified as vulnerable; (c) number of tree species; (d) Shannon-Wiener index of species diversity (calculated as $\Sigma p \log _{\mathrm{e}} p$, where $p$ is the proportion of each taxon in the sample; Krebs 1998); (e) total number of individuals in the sample; (f) percentage of maximum attainable species richness in a hypothetical system of protected areas, as estimated by a simulation of a reserve network selection.

When appropriate, sequential Bonferroni corrections were performed on multiple statistical tests conducted on the same data set.

\section{Results}

Compared with spatial controls, taxonomic A controls and taxonomic B controls, sites occupied by top predators held greater numbers of avian species (for all raptor species $t_{48} \geq 3 \cdot 13, P<0 \cdot 009$; Fig. 1 a), greater numbers of vulnerable avian species $\left(t_{48} \geq 3 \cdot 10, P<0 \cdot 01\right.$; Fig. $\left.1 b\right)$ and greater number of tree species $\left(t_{48} \geq 3.18, P<0.003\right.$, except for one comparison for which $t=2 \cdot 06, P<0 \cdot 14$; Fig. 1c). Compared with all types of control sites, top predator sites also showed higher values of the Shannon diversity index, calculated on all avian species $\left(t_{48} \geq 3 \cdot 31\right.$, $P<0.009$; Fig. 1d) or on only vulnerable avian species $\left(t_{48} \geq 3.94, P<0.01\right.$, except for one comparison for which $\left.t_{48}=2 \cdot 96, P<0.07\right)$, respectively. In contrast, none of the biodiversity estimates collected at taxonomic A or B control sites was significantly higher than those collected at their associated spatial controls (for all species, $t_{48} \leq 2 \cdot 45, P \geq 0 \cdot 16$; Fig. $\left.1 \mathrm{a}-\mathrm{d}\right)$.

Analyses with invertebrates as surrogates of biodiversity (only available for the grassland and farmland habitat types) confirmed the findings from those using birds and trees: for the scops owl and long-eared owl, the richness and diversity of diurnal butterflies species was higher at sites occupied by the owls than at spatial controls, taxonomic A controls and taxonomic B controls (for all comparisons $t_{48} \geq 2 \cdot 49, P<0 \cdot 05$ ). The comparison between the taxonomic $\mathrm{A}$ and $\mathrm{B}$ control sites and their associated spatial controls was not significant (for richness and Shannon-Wiener index, $t_{48} \leq 0 \cdot 67, P \geq 0 \cdot 50$ ).

The presence of top predators indicated more than biodiversity alone. Sites holding each of the six raptor species also revealed higher densities of individual birds (all species together) and of individual butterflies (all species together) than any of the spatial or taxonomic control sites (for all comparisons, $t_{48} \geq 2.94, P<0.05$; Fig. 1e). In contrast, taxonomic A and B control sites showed no greater numbers of individual birds or butterflies than their own spatial control sites $\left(t_{48} \leq 2 \cdot 06\right.$, $P \geq 0.09$; Fig. 1e).

The reserve network selection exercise showed that the number of sites required to include all species in a hypothetical protected areas system was lower when using sites occupied by top predators than when using spatial control sites or taxonomic control sites (for all comparisons, $t_{10} \geq 2 \cdot 82, P<0.05$ ). The difference between taxonomic control sites and their associated spatial controls was not significant $\left(t_{10} \leq 1 \cdot 12, P \geq 0 \cdot 29\right)$. Furthermore, the efficiency of each simulated network of protected areas, as expressed by the percentage of maximum attainable biodiversity, was higher for top predator sites than for spatial control sites or for taxonomic control sites $\left(t_{10} \geq 4.02, P<0.01\right.$; Fig. 1f), while it did not differ between taxonomic control sites and their associated spatial controls $\left(t_{10} \leq 1 \cdot 01\right.$, $P \geq 0 \cdot 34$; Fig. 1f). On average, networks planned using lower trophic level species failed to represent $34 \%$ of the maximum species richness in each sample, against only 5\% for networks planned using top predators (Fig. 1f).

\section{Discussion}

Overall, sites occupied by each of the top predators used in this study had a higher diversity of vulnerable and 

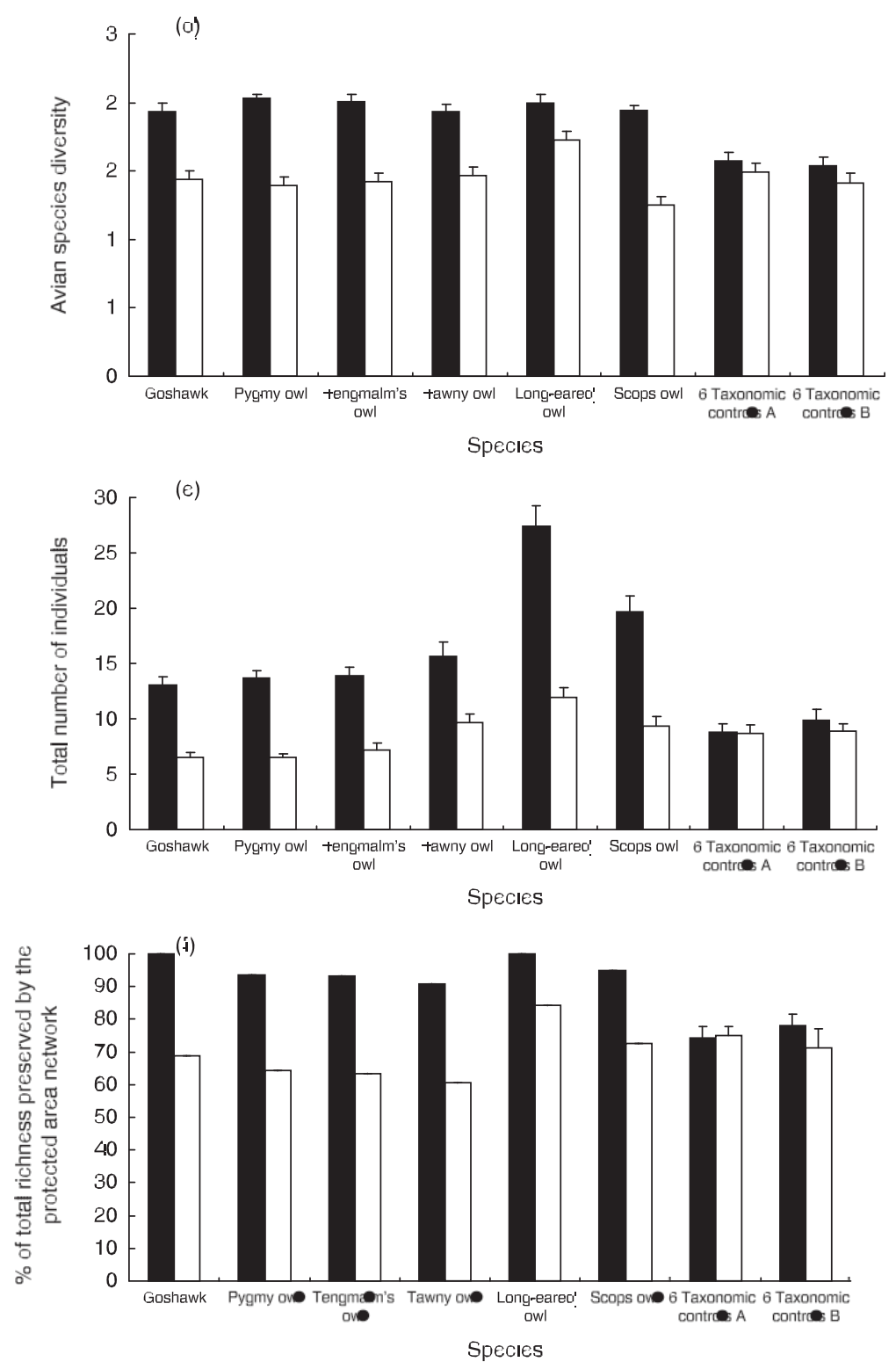

Fig. 1. Continued associations suggested that the observed patterns were not local phenomena or simple chance results.

There are numerous reasons why top predators might be consistently associated with high biodiversity levels. First, the predators may select such sites: the occurrence, density and productivity of many top predators is dependent on whole ecosystem productivity, which affects food availability in a bottom-up manner (Newton et al. 1977; Carroll, Noss \& Paquet 2001; Sergio, Marchesi \& Pedrini 2003a,b) and often has a major influence on biodiversity value (Rosenzweig 1995; Gaston 1996). Secondly, top predators are often keystone species, their impact on other biota cascading down through the ecosystem and ultimately affecting community structure and biodiversity levels, with positive effects on species numbers (Terborgh et al.1999; Schmitz, Hambäck \& Beckerman 2000; Berger et al. 2001; Duffy 2002). Thirdly, their large per-pair area requirements make them umbrella species (Newton 1979; Gittleman et al. 2001), in that sites capable of supporting viable populations of top predators will automatically be able to support populations of smaller, less area-demanding species. Fourthly, predators are often sensitive to major ecosystem dysfunctions, such as chemical pollution, habitat alteration and other anthropogenic disturbances (Newton 1979, 1998; Thiollay 1989; Sergio et al. 2004b). Fifthly, predators often select sites with high topographic and habitat complexity (Sergio, Marchesi \& Pedrini 2004a; Sergio et al. 2004b, 2005 and references therein), which also often promotes high biodiversity (Rosenzweig 1995; Gaston 1996). Sixthly, most top predators have diets dominated by relatively few main prey species but including a large number of minor prey species; richer (prey) communities will thus allow prey switching during periods of scarcity of the main prey, ultimately favouring population persistence (Steenhof \& Kochert 1988). Furthermore, because each of such prey species in turn depends on a complex suite of biotic and abiotic conditions, the presence of a predator implies the persistence of such diffuse complexity. Seventhly, some top predators may provide spatial refugia for other species by selectively attacking or deterring the potential predators or competitors of such species (Bogliani, Sergio \& Tavecchia 1999; Quinn \& Kokorev 2002). Eighthly, top predators may indirectly provide essential resources for other species, such as carrion for scavengers (Wilmers et al. 2003). All the above causal and indirect links contribute to making top predators potential synthetic capsules of their supporting ecosystem. The strategic and ecological importance of finding species that may simultaneously meet the criteria of different surrogate schemes (e.g. flagship, keystone, umbrella and biodiversity indicator) has been stressed numerous times (Caro \& O’Doherty 1999; Entwistle \& Dunstone 2000; Carignan \& Villard 2002; Norris \& Pain 2002). It is difficult to think of a lower trophic level species that could simultaneously meet a similar number of requirements.

Our results offer evidence of a tight association, at least in one diverse region, between the occurrence of 
apex predators and high biodiversity value, providing a direct link between the strategic exploitation of flagship species and the delivery of wider biodiversity conservation goals. More data from other systems will be needed to assess further the generality of our findings and reach firmer conclusions about the potential ecosystem-level efficacy of conservation plans based on charismatic top predators.

\section{Acknowledgements}

We thank T. Caro, S. Thirgood and an anonymous referee for comments on a previous draft of the manuscript. This study was included in 'Project Biodiversità', funded by the Autonomous Province of Trento.

\section{References}

Andelman, S.J. \& Fagan, W.F. (2000) Umbrellas and flagships: efficient conservation surrogates or expensive mistakes? Proceedings of the National Academy of Sciences USA, 97, 5954-5959.

Berger, J., Stacey, P.B., Bellis, L. \& Johnson, M.P. (2001) A mammalian predator-prey imbalance: grizzly bear and wolf extinction affect avian neotropical migrants. Ecological Applications, 11, 947-960.

Bibby, C.J., Burgess, N.D. \& Hill, D.A. (1992) Bird Census Techniques. Academic Press, London, UK.

Biles, C.M. \& Noon, B.R. (1990) The spotted owl. The UMAP Journal, 11, 99-109.

Bogliani, G., Sergio, F. \& Tavecchia, G. (1999) Nesting association with hobby falcons: advantages and choice rules of the woodpigeon. Animal Behaviour, 57, 125-131.

Carignan, V. \& Villard, M. (2002) Selecting indicator species to monitor ecological integrity: a review. Environmental Monitoring and Assessment, 78, 45-61.

Caro, T.M. \& O’Doherty, G. (1999) On the use of surrogate species in conservation biology. Conservation Biology, 13, 805-814.

Caro, T.M., Engilis, A. Jr, Fitzhebert, E. \& Gardner, T. (2004) Preliminary assessment of the flagship concept at a small scale. Animal Conservation, 7, 63-70.

Carroll, C., Noss, R.F. \& Paquet, P.C. (2001) Carnivores as focal species for conservation planning in the Rocky Mountain region. Ecological Applications, 11, 961-980.

Cramp, S. \& Simmons, K.E.L. (1980) Handbook of the Birds of Europe, the Middle East and North Africa, Vol. 2. Oxford University Press, Oxford, UK.

Duffy, J.E. (2002) Biodiversity and ecosystem function: the consumer connection. Oikos, 99, 201-219.

Entwistle, A. \& Dunstone, N. (2000) Priorities for the Conservation of Mammalian Diversity: Has the Panda Had its Day? Cambridge University Press, Cambridge, UK.

Gaston, K.J. (1996) Biodiversity. A Biology of Numbers and Difference. Blackwell Science, Oxford, UK.

Gittleman, J.L., Funk, S.M., Macdonald, D. \& Wayne, R.K. (2001) Carnivore Conservation. Cambridge University Press, Cambridge, UK.

Hooge, P.N. \& Eichenlaub, B. (1997) Movement. Animal Movement Extension to ArcView, Version 1·1. Alaska Biological Science Center, US Geological Survey, Anchorage, AK.

Jeggins, M.D. (2000) Gap analysis: concepts, methods and recent results. Landscape Ecology, 15, 5-20.

Kerr, J.T. (1997) Species richness, endemism, and the choice of protected areas for conservation. Conservation Biology, 11, 1094-1100.
Kerr, J.T., Sugar, A. \& Packer, L. (2000) Indicator taxa, rapid biodiversity assessment, and nestedness in an endangered ecosystem. Conservation Biology, 14, 1726-1734.

Krebs, C.J. (1998) Ecological Methodology. HarperCollins, New York, NY.

Leader-Williams, N. \& Dublin, H.T. (2000) Charismatic megafauna as 'flagship species'. Priorities for the Conservation of Mammalian Diversity: Has the Panda Had its Day? (eds A. Entwistle \& N. Dunstone), pp. 53-81. Cambridge University Press, Cambridge, UK.

Linnell, J.D.C., Swenson, J.E. \& Andersen, R. (2000) Conservation of biodiversity in Scandinavian boreal forests: large carnivores as flagships, umbrellas, indicators, or keystones? Biodiversity and Conservation, 9, 857-868.

McNeely, J.A. (2000) Practical approaches for including mammals in biodiversity conservation. Priorities for the Conservation of Mammalian Diversity: Has the Panda Had its Day? (eds A. Entwistle \& N. Dunstone), pp. 355-367. Cambridge University Press, Cambridge, UK.

Martin, R.B. \& de Meulenaer, T. (1988) Survey of the Status of the Leopard (Panthera pardus) in Sub-Saharan Africa. CITES Secretariat, Lausanne, Switzerland.

Mishra, C. (1997) Livestock depredation by large carnivores in the Indian trans-Himalaya: conflict perceptions and conservation projects. Environmental Conservation, 24, $338-$ 343.

Murphy, D.D. \& Noon, B.R. (1992) Integrating scientific methods with habitat conservation planning: reserve design for northern spotted owls. Ecological Applications, 2, 3-17.

Newton, I. (1979) Population Ecology of Raptors. T. \& A. D. Poyser, Berkhamsted, UK.

Newton, I. (1998) Population Limitation in Birds. Academic Press, London, UK.

Newton, I., Marquiss, M., Weir, D.N. \& Moss, D. (1977) Spacing of sparrowhawk nesting territories. Journal of Animal Ecology, 46, 425-441.

Norris, K. \& Pain, D.J. (2002) Conserving Bird Biodiversity: General Principles and Their Application. Cambridge University Press, Cambridge, UK.

Patterson, B.D., Kasiki, S.M., Selempo, E. \& Kays, R.W. (2004) Livestock predation by lions (Panthera leo) and other carnivores on ranches neighboring Tsavo National Parks, Kenya. Biological Conservation, 119, 507-516.

Quinn, J.L. \& Kokorev, Y. (2002) Trading-off risks from predators and from aggressive hosts. Behavioral Ecology and Sociobiology, 51, 455-460.

Reading, R.P. \& Clark, T.W. (1996) Carnivore reintroductions: an interdisciplinary examination. Carnivore Behavior, Ecology, and Evolution (ed. J.L. Gittleman), pp. 296-336. Cornell University Press, Ithaca, NY.

Rosenzweig, M.L. (1995) Species Diversity in Space and Time. Cambridge University Press, Cambridge, UK.

Schmitz, O.J., Hambäck, P.A. \& Beckerman, A.P. (2000) Trophic cascades in terrestrial ecosystems: a review of the effects of carnivore removals on plants. American Naturalist, 155, 141-153.

Sergio, F., Marchesi, L. \& Pedrini, P. (2003a) Spatial refugia and the coexistence of a diurnal raptor with its intraguild owl predator. Journal of Animal Ecology, 72, 232-245.

Sergio, F., Marchesi, L. \& Pedrini, P. (2003b) Reconciling the dichotomy between single species and ecosystem conservation: black kites (Milvus migrans) and eutrophication in pre-alpine lakes. Biological Conservation, 110, 101-111.

Sergio, F., Marchesi, L. \& Pedrini, P. (2004a) Integrating individual habitat choices and regional distribution of a biodiversity indicator and top predator. Journal of Biogeography, 31, 619-628.

Sergio, F., Marchesi, L., Pedrini, P., Ferrer, M. \& Penteriani, V. (2004b) Electrocution alters the distribution and density of a top predator, the eagle owl Bubo bubo. Journal of Applied Ecology, 41, 836-845. 
Sergio, F., Rizzolli, F., Marchesi, L. \& Pedrini, P. (2004c) The importance of interspecific interactions for breeding habitat selection: peregrine falcons seek proximity to raven nests. Ecography, 27, 818-826.

Sergio, F., Scandolara, C., Marchesi, L., Pedrini, P. \& Penteriani, V. (2005) Effect of agro-forestry and landscape changes on common buzzards (Buteo buteo) in the Alps. Animal Conservation, 7, 17-25.

Sokal, R.R. \& Rohlf, F.J. (1981). Biometry. W. H. Freeman, New York, NY.

Steenhof, K. \& Kochert, M.N. (1988) Dietary responses of three raptor species to changing prey densities in a natural environment. Journal of Animal Ecology, 57, 3748.

Terborgh, J., Estes, J.A., Paquet, P., Ralls, K., Boyd-Heger, D., Miller, B.J. \& Noss, R.F. (1999) The role of top carnivores in regulating terrestrial ecosystems. Continental Conservation: Scientific Foundations of Regional Reserve Networks (eds M.E. Soulé \& J. Terborgh), pp. 39-64. Island Press, Covelo, CA.

Thiollay, J.M. (1989) Area requirements for the conservation of rain forest raptors and game birds in French Guyana. Conservation Biology, 3, 128-137.
Tolman, T. (1997) Collins Field Guide to Butterflies of Britain and Europe. HarperCollins, London, UK.

Tucker, G.M. \& Heath, M.F. (1994) Birds in Europe. Their Conservation Status. BirdLife International, Cambridge, UK.

Western, D. (1984) Amboseli National Park: human values and the conservation of a savanna ecosystem. National Parks, Conservation and Development: the Role of Protected Areas in Sustaining Society (eds J.A. McNeely \& K.R. Miller), pp. 93-100. Smithsonian Institution Press, Washington, DC.

White, P.C.L., Gregory, K.W., Lindley, P.J. \& Richards, G. (1997) Economic values of threatened mammals in Britain: a case study of the otter Lutra lutra and the water vole Arvicola terrestris. Biological Conservation, 82, 345-354.

Wilmers, C.C., Crabtree, R.L., Smith, D.W., Murphy, K.M. \& Getz, W.M. (2003) Trophic facilitation by introduced top predators: grey wolf subsidies to scavengers in Yellowstone National Park. Journal of Animal Ecology, 72, 909-916.

Yalden, D.W. (1993) The problems of reintroducing carnivores. Symposia of the Zoological Society of London, 65, 289-306.
(C) 2006 The Authors. Journal compilation (C) 2006 British Ecological Society, Journal of Applied Ecology, 43, 1049-1055 